\title{
Variações metodológicas na contagem de células somáticas do leite de ovelhas da raça Santa Inês
}

\author{
Methodology variations in milk somatic cell count from Santa Ines ewes \\ Maiara Garcia Blagitz ${ }^{I^{*}}$ Nilson Roberti Benites ${ }^{\text {II }}$ Camila Freitas Batista $^{\mathrm{I}}$ \\ Fernando Nogueira Souza ${ }^{\text {III }}$ Ricardo Augusto Dias ${ }^{\text {II }}$ Viviani Gomes $^{\mathrm{I}}$ \\ Alice Maria Melville Paiva Della Libera ${ }^{\mathrm{I}}$
}

\section{- NOTA -}

RESUMO

O presente estudo objetivou avaliar a correlação entre a contagem de células somáticas (CCS) automática e a CCS microscópica direta por diferentes colorações no leite de ovelhas da raça Santa Inês. Avaliou-se a CCS automática por citometria de fluxo, e a CCS microscópica foi realizada por esfregaços lácteos corados com as colorações de BroadhurstPaley (BP), Hematoxilina-eosina (HE) e Rosenfeld. Os valores logarítmicos da CCS microscópica pela coloração de BP $e$ Rosenfeld foram superiores aos valores logarítmicos da CCS automática e a CCS microscópica pela coloração de HE $(P<0,0001)$, e os valores logarítmicos da CCS pela coloração de $H E$ foram inferiores aos valores logarítmicos da CCS automática $(P<0,0001)$. As correlações entre os valores logarítmicos da CCS automática e os valores logarítmicos das CCS microscópica pelas colorações de HE, BP e Rosenfeld foram de 0,774, 0,803 e 0,859 $(P<0,0001)$, respectivamente. Os valores logarítmicos reais da CCS microscópica e aqueles estimados pela CCS automática, considerando as equações das curvas por regressão quadrática, não foram estatisticamente diferentes pelas colorações de $H E$ $(P=0,90), B P(P=0,09)$ e Rosenfeld $(P=0,23)$. Conclui-se que a metodologia influencia a CCS no leite de ovinos e propõese a utilização da equação da curva para estimação da CCS automática a partir dos valores da CCS microscópica, quando colorações não específicas para o ácido desoxirribonucleico são aplicadas para avaliação da celularidade do leite no diagnóstico da mastite em ovinos.

Palavras-chave: contagem de células somáticas, leite, mastite, ovelhas.

\begin{abstract}
The present study was designed to assess the correlation among the automatic somatic cell count and the microscopic somatic cell count using the Broadhurst-Paley (BP), Hematoxilin-eosin (HE) and Rosenfeld dyes. The milk smears were stained with $B P, H E$ and Rosenfeld and the automatic cell count was performed by flow cytometry. The mean logarithmic microscopic SCC by BP and Rosenfeld was higher than the values from automatic SCC and microscopic SCC by HE $(P<0.0001)$. Indeed, the mean values from microscopic SCC using the HE was lower than the automatic cell count $(P<0.0001)$. The correlation among the automatic cell count and the microscopic SCC using the HE, BP and Rosenfeld dyes were 0.774, 0.803 e 0.859 $(P<0.0001)$, respectively. The automatic SCC values and the estimated automatic SCC applying the quadratic equation using the results of the microscopic SCC using the HE $(P=0.90), B P$ $(P=0.09)$ and Rosenfeld $(P=0.23)$ dyes were not different. Thus, it can be concluded that the SCC was influenced by the methodology applied, and nonspecific stains used for microscopic SCC can be used to assess udder health in ewes if an equation is applied to estimate automatic SCC.
\end{abstract}

Key words: mastitis, milk, sheep, somatic cell count.

A contagem de células somáticas (CCS) do leite de ovelhas abrange diferentes elementos celulares normalmente presentes no leite,

'Laboratório de Imunodiagnóstico, Departamento de Clínica Médica, Faculdade de Medicina Veterinária e Zootecnia (FMVZ), Universidade de São Paulo (USP), Av. Prof. Dr. Orlando Marques de Paiva 87, Cidade Universitária, 05508-270, São Paulo, SP, Brasil. E-mail: magblagitz@uol.com.br. *Autor para correspondência.

"Departamento de Medicina Veterinária Preventiva e Saúde Animal, FMVZ, USP, São Paulo, SP, Brasil.

"IIDepartamento de Medicina Veterinária Preventiva, Escola de Veterinária (EV), Universidade Federal de Minas Gerais (UFMG), Belo Horizonte, MG, Brasil. 
compreendendo os leucócitos e as células epiteliais. No entanto, por ser considerada glândula com secreção apócrina, o leite dos pequenos ruminantes apresenta partículas citoplasmáticas com diâmetro e morfologia semelhantes aos leucócitos (GOMES et al., 2010; SOUZA et al., 2012).

A CCS (automática e microscópica) uma ferramenta de baixo custo e de fácil e rápida execução, quando comparada à cultura bacteriológica (SOUZA et al., 2012). A contagem de células somáticas automática (CCS automática) é realizada por citometria de fluxo e apresenta altas correlações com a CCS microscópica quando utilizado colorações específicas para o ADN (GONZALO et al., 1993; PETERSSON et al., 2011). Para a realização da CCS microscópica, há possibilidade da utilização de diversos protocolos de coloração, porém, em pequenos ruminantes, devido à presença dos corpúsculos citoplasmáticos, a CCS microscópica exige a utilização de colorações específicas para o ADN, como a May-Grünwald-Giemsa e verde de metil e pironina-Y, que são técnicas mais trabalhosas do que outras colorações amplamente utilizadas na CCS microscópica do leite de bovinos. As colorações utilizadas para bovinos, não específicas para o ADN, poderiam ser utilizadas em ovinos, caso os valores da CCS microscópica por estas colorações fossem estimados por uma metodologia reconhecida, como a CCS automática. Assim, a aplicação de uma equação para estimação da celularidade do leite de ovinos através da CCS microscópica por colorações não específicas permitiria a melhor utilização dessa ferramenta no diagnóstico da mastite, já que os corpúsculos citoplasmáticos são encontrados no leite de ovelhas em valores bem inferiores aos do leite de cabras (SOUZA et al., 2012). Dessa forma, o presente trabalho objetivou avaliar a correlação entre as CCS automática pelo método de citometria de fluxo e a CCS microscópica direta pelas colorações de Broadhurst-Paley, Hematoxilina-eosina e Rosenfeld do leite de ovelhas da raça Santa Inês. Foram utilizadas 510 amostras de leite de ovelhas da raça Santa Inês em diferentes fases da lactação, oriundas de rebanhos localizados no estado de São Paulo. Essas amostras foram destinadas a CCS automática e CCS microscópica pelas colorações de hematoxilinaeosina (HE) e Broadhurst-Paley (BP) e parte dessas amostras de leite $(n=213)$ foram designadas a CCS microscópica pela coloração de Rosenfeld.

As colorações de HE, Rosenfeld e BP foram realizadas para a determinação da CCS microscópica direta, conforme técnica descrita por Benites et al., (2001), assim como as colorações de HE e BP (BENITES et al. 2001). Procedimentos semelhantes foram utilizados para a coloração de Rosenfeld. Efetuaram-se as contagens de células presentes em cem campos visuais das lâminas confeccionadas, e multiplicou-se o valor encontrado pelo fator microscópico previamente calculado, expressando o resultado em número de células somáticas por $\mathrm{mL}$ de leite.

As amostras destinadas a CCS automática foram coletadas com Bronopol $^{\circledR}$ (2-bromo2nitropropane-1-diol). A CCS automática foi realizada por citometria de fluxo, utilizando o aparelho Somacount 300 (Bentley Instruments ${ }^{\circledR}$ Inc., EUA) calibrado com leite de bovinos, no qual se detectou a fluorescência do brometo de etídeo que forma um complexo com o ácido desoxirribonucleico no núcleo celular.

A análise estatística foi realizada utilizando os programas Software Statistical Package for Social Sciences (SPSS) versão 9.0 e GraphPad Prism 5.0 (GraphPad software, Inc., San Diego, EUA). A normalidade foi verificada pelo teste de Kolmogorov-Smirnov. As comparações entre as médias da CCS automática e a CCS microscópica com as diferentes colorações foram realizadas pelo teste Wilcoxon para amostras pareadas com nível de $5 \%$ de significância, sendo os valores apresentados como média \pm desvio-padrão. Os valores da CCS foram transformados em valores logarítmicos, já que os dados não apresentaram distribuição normal. As correlações entre a CCS automática e microscópica direta pelas colorações de HE, Rosenfeld e BP foram determinadas pela correlação de Spearman. As funções das curvas de calibrações foram previamente originadas da aplicação de modelos de regressão linear, logarítmica, inversa, polinomial quadrática, polinomial cúbica e exponencial. A função que apresentou o maior coeficiente de correlação (r) foi considerada como a equação que melhor se adequaria à curva para determinação da CCS automática, considerando os valores encontrados para a CCS microscópica, utilizando as colorações de HE, BP e Rosenfeld.

Os valores logarítmicos da CCS microscópica pela coloração de $\mathrm{HE}(4,98 \pm 0,91)$ foram inferiores aos valores logarítmicos da CCS automática $(5,57 \pm 0,70) \quad(\mathrm{P}<0,0001)$. No entanto, os valores logarítmicos da CCS microscópica pela coloração de BP $(5,80 \pm 0,76)$ foram superiores aos valores logarítmicos da CCS automática e a CCS 
microscópica pela coloração de $\mathrm{HE}(\mathrm{P}<0,0001)$ nas 510 amostras analisadas. Do mesmo modo, BARBOSA et al. (2004), ao determinarem a celularidade do leite de ovelhas, observaram menor celularidade pela CCS microscópica com a coloração de HE que a CCS automática e a CCS microscópica pela coloração de BP. A maior celularidade da CCS microscópica pela coloração de BP foi relacionada à maior contagem de leucócitos mononucleares, já que as contagens de leucócitos polimorfonucleares pela CCS microscópica, utilizando as colorações de HE e $\mathrm{BP}$, não diferiram, sendo proposto que o núcleo das células mononucleares impregna menos corante do que o núcleo das células polimorfonucleares, levando a maior dificuldade na visualização celular.

Ao considerar as 213 amostras coradas por Rosenfeld, os valores logarítmicos da CCS $(5,78 \pm 0,64)$ foram superiores a CCS automática $(5,67 \pm 0,58 ; \mathrm{P}<0,0001)$ e a CCS microscópica pela coloração de $\mathrm{HE}(5,06 \pm 0,87 ; \mathrm{P}<0,0001)$, porém não diferiu da CCS microscópica pela coloração de BP $(5,83 \pm 0,66 ; \mathrm{P}=0,15)$. Similarmente, GOMES et al. (2010), em ovelhas da raça Lacaune, observaram que os valores da CCS microscópica pela coloração de Rosenfeld foram superiores ao da CCS automática, o que deve-se, provavelmente, ao fato de a coloração de Rosenfeld não ser específica para células nucleadas, não permitindo a correta e precisa diferenciação entre células somáticas e os corpúsculos citoplasmáticos presentes no leite dessa espécie.

As correlações entre os valores logarítmicos da CCS automática e os valores logarítmicos das CCS microscópica pelas colorações de HE, BP e Rosenfeld foram de 0,774, 0,803 e 0,859 $(\mathrm{P}<0,0001)$, respectivamente. Ademais, a correlação entre as CCS microscópica pelas colorações de HE e BP foi de $0,743(\mathrm{P}<0,0001)$. As correlações entre a CCS microscópica pela coloração de Rosenfeld e as CCS microscópica pelas colorações de HE e BP foram de 0,786 e 0,788 ( $\mathrm{P}<0,0001)$, respectivamente. Essas correlações entre a CCS automática e a CCS microscópica são inferiores às correlações descritas por GONZALO et al. (1993), utilizando corante específico para o ADN.

A regressão polinomial quadrática foi a que mais se adequou ao modelo proposto para a determinação das curvas da CCS automática, considerando as CCS microscópica pelas colorações de HE ( $\mathrm{r}=0,81 ; \mathrm{P}<0,0001)$ (Figura 1), BP $(\mathrm{r}=0,71$; $\mathrm{P}<0,0001)$ e Rosenfeld $(\mathrm{r}=0,87 ; \mathrm{P}<0,0001)$ (Figura $2 \mathrm{~A}$ e 2B). As curvas para determinação da CCS automática, considerando os valores encontrados pela
CCS microscópica, foram, então: $\mathrm{Y}=\mathrm{b}_{2} \cdot \mathrm{x}^{2}+\mathrm{b}_{1} \cdot \mathrm{x}+\mathrm{a}$, onde: $\mathrm{Y}=\log$ CCS microscópica; $\mathrm{x}=\log \mathrm{CCS}$ automática; $b_{2}: 0,287 ; 0,178 ; 0,17 ; b_{1}:-2,112 ;-1,256 ;-1,001 ; a:$ 7,$709 ; 7,1665 ; 6,003$, sendo os valores de $a, b_{1}$ e $b_{2}$ para as CCS microscópica pelas colorações de HE, BP e Rosenfeld, respectivamente.

Os valores logarítmicos reais da CCS microscópica e da CCS automática estimados pela CCS microscópica, considerando as equações das curvas não foram estatisticamente diferentes pelas colorações de $\mathrm{HE}(4,99 \pm 0,82 ; \mathrm{P}=0,90)$, BP $(5,78 \pm 0,54 ; \quad \mathrm{P}=0,09)$ e Rosenfeld $(5,79 \pm 0,56$; $\mathrm{P}=0,23)$. Portanto, propõe-se a utilização da equação da curva para determinação da CCS automática a partir dos valores da CCS microscópica, utilizando colorações não específicas para o ADN, já que não se observou diferença estatística entre a CCS automática e os valores ajustados pela equação da curva para a CCS microscópica, utilizando as colorações de BP, HE e Rosenfeld. Embora a curva de calibração da CCS automática entre os diferentes laboratórios pode apresentar variações, ela deve ser considerada. Dessa forma, conclui-se que a aplicação da equação de calibração na CCS do leite de ovelhas deve ser aplicada considerando as diferentes colorações utilizadas na CCS microscópica, o que permite o uso dessa ferramenta de baixo custo, de fácil e rápida execução no controle e diagnóstico da mastite.

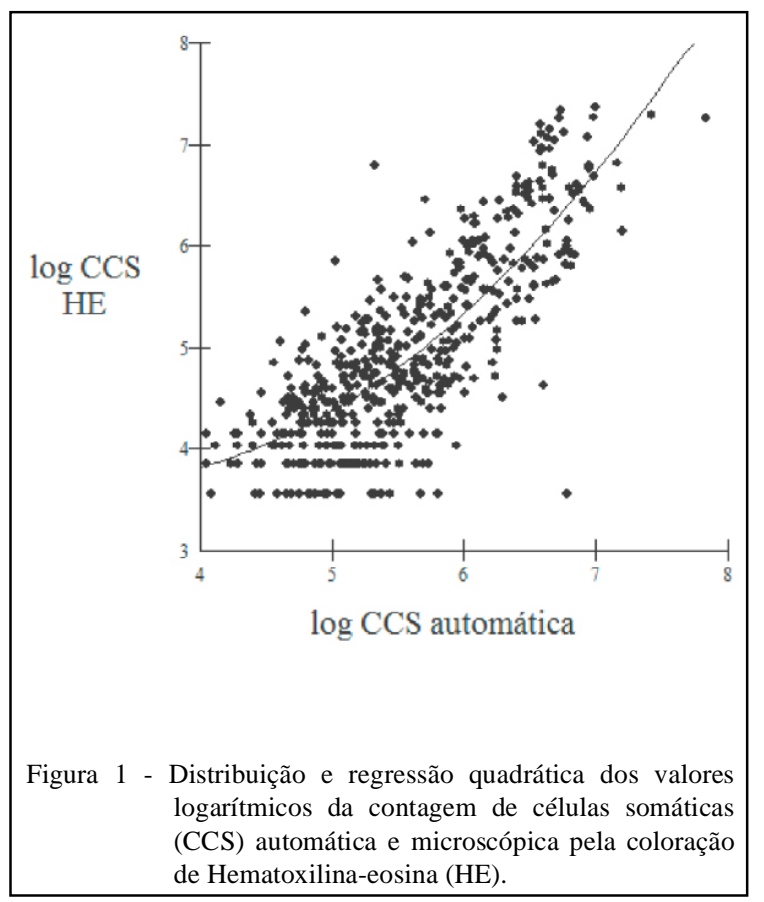




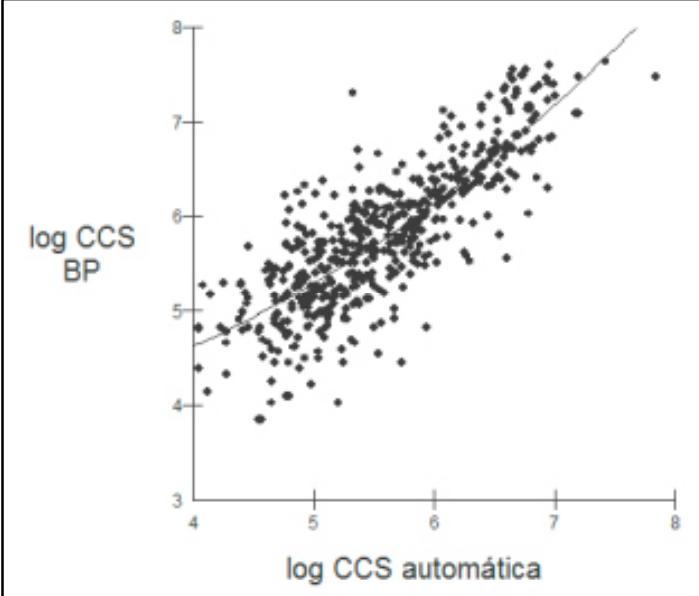

A)

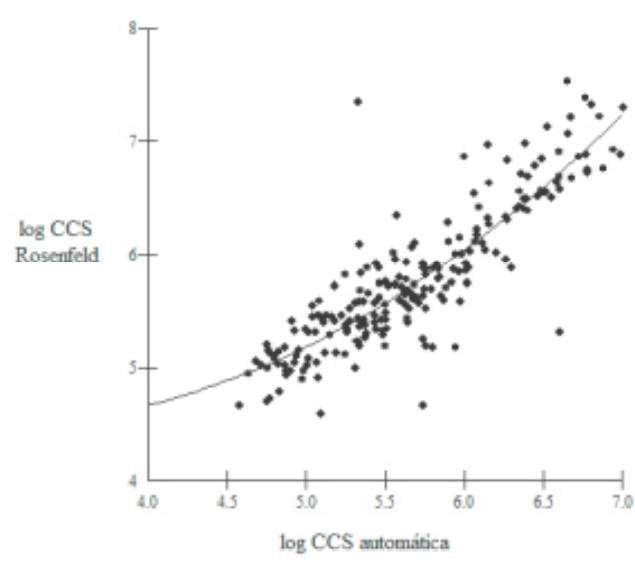

B)

Figura 2 - A) Distribuição e regressão quadrática dos valores logarítmicos da contagem de células somáticas (CCS) automática e microscópica pela coloração de Broadhurt-Paley (BP) (A) e microscópica pela coloração de Rosenfeld (B).

\section{AGRADECIMENTOS}

À Fundação de Amparo à Pesquisa do Estado de São Paulo (FAPESP), pelo apoio financeiro.

\section{REFERÊNCIAS}

BARBOSA, D.A. et al. Comparação entre a contagem de células somática em leite de ovinos empregando técnicas direta e indireta. Arquivos do Instituto Biológico, v.71, p.284-287, 2004.

BENITES, N.R. et al. Modificação da técnica de contagem de células somáticas de Prescott \& Breed utilizando-se a coloração de Hematoxilina e Eosina. Napagma, v.4, n.3, p.6-9, 2001.

GOMES, V. et al. Contagem automática e microscópica direta das células somáticas do leite de ovelhas da raça Lacaune, utilizando como corantes o Rosenfeld e verde de metil pironona-Y. Ciência Animal Brasileira, v.11, p.162-167, 2010. Disponível em: <http:// www.revistas.ufg.br/index.php/vet/article/view/4627>. Acesso em: 25 maio, 2012.

GONZALO, C. et al. Use of Fossomatic method to determine somatic cell counts in sheep milk. Journal of Dairy Science, v.76, p.115-119, 1993. Disponível em: <http://download.journals.elsevierhealth.com/ pdfs/journals/0022-0302/PIIS0022030293773300.pdf>. Acesso em: 25 maio, 2012. doi: 10.3168/jds.S0022-0302(93)77330-0.

PETERSSON, K.H. et al. Evaluation of confirmatory stains used for direct and microscopic somatic cell counting of sheep milk. Journal of Dairy Science, v.94, n.4, p.1908-1912, 2011. Disponível em: <http://www.journalofdairyscience.org/article/ S0022-0302(11)00159-7/fulltext>. Acesso em: 25 maio, 2012. doi: $10.3168 /$ jds.2010-3574

SOUZA, F.N. et al. Somatic cell count in small ruminants: friend or foe? Small Ruminant Research, v.107, p.6575, 2012. Disponível em: <http://dx.doi.org/10.1016/j. smallrumres.2012.04.005>. Acesso em: 25 maio, 2012. doi: 10.1016/j.smallrumres.2012.04.005. 